\title{
Nível de aderência na evidenciação das notas explicativas de contratos de construção segundo deliberação CVM $n^{\circ} 691 / 12$
}

Dylliane Maria Alessi Pontarolo

dylliane@hotmail.com

Universidade Estadual do Centro Oeste (UNICENTRO), Irati, Paraná, Brasil

Ana Léa Macohon Klosowski analeaklosowski@hotmail.com
Universidade Estadual do Centro Oeste (UNICENTRO), Irati, Paraná, Brasil

\section{Flávio Ribeiro}

flavioribeiro@unicentro.br

Universidade Estadual do Centro Oeste (UNICENTRO), Irati, Paraná, Brasil

Telma Regina Stroparo telmastroparo@yahoo.com.br Universidade Estadual do Centro Oeste (UNICENTRO), Irati, Paraná, Brasi

\author{
RESUMO
}

A pesquisa apresenta como objetivo, identificar o grau de aderência na evidenciação, em notas explicativas, dos contratos de construção segundo a Deliberação CVM no. 691/12 em empresas brasileiras de capital aberto do segmento de Construção Civil. Para isso foram analisadas as empresas do segmento de construção civil com maior representatividade no Índice BM\&FBOVESPA Imobiliário. A pesquisa caracterizou-se como descritiva quanto ao objetivo e bibliográfica e documental quanto aos procedimentos, além que tratar de um estudo qualitativo. $O$ instrumento de pesquisa foi construído com base nas informações extraídas da Deliberação CVM no 691/12. Os resultados sugerem que apenas uma das empresas analisadas evidenciaram todas as informações sugeridas pela deliberação (MRV). Notou-se, também, que a principal ausência de informações refere-se a classificação dos contratos (Etapa 01), montante de receitas dos contratos (Etapa 02) e valor bruto devido pelo contratante e ao contratante (Etapa 3). As Etapas $04 \mathrm{e}$ 05 foram atendidas integralmente pelas empresas analisadas.
\end{abstract}

PALAVRAS-CHAVE: Evidenciação contábil. Segmento de Construção Civil. Notas Explicativas. 


\section{INTRODUÇÃO}

O processo de globalização foi determinante para a evolução da contabilidade internacional. A compreensão das diversas práticas contábeis levou a constatação de que processos diferentes conduziam a resultados divergentes. Assim, era comum ocorrer situações em que uma empresa sediada em um país, ao apurar suas demonstrações contábeis com base nas normas daquele país, apresentava resultados divergentes aos que conseguiria se apurasse suas demonstrações em concordância com as normas do país sede (NIYAMA; SILVA, 2011).

A convergência contábil é fruto do trabalho de duas das principais entidades contábeis mundiais: o FASB (Financial Accounting Standards Board) e o IASB (International Accounting Standards Board). O FASB é uma entidade privada, criado em meados da década de 1970, responsável pela edição das normas contábeis norte-americana. O IASB também trata-se de uma entidade privada, mas de abrangência internacional, possui mais de 100 países filiados, inclusive 0 Brasil, e é responsável pela emissão das normas internacionais de contabilidade (IAS e IFRS).

No Brasil, o Comitê de Pronunciamentos Contábeis (CPC) é o órgão responsável pela emissão das normas contábeis em convergências com as normas internacionais. Entre essas normas estão: o Comitê de Pronunciamento Contábil CPC 17 - Contratos de Construção e a Interpretação Técnica ICPC 02 Contratos de construção do setor imobiliário, baseada na norma internacional IFRIC 15.

A aderência na adoção das normais internacionais de contabilidade (IFRS) pelas empresas brasileiras tem sido explorada por pesquisadores nacionais (BARCELOS, 2011; SILVA; SOEIRO; ARAÚJO, 2013). Barcelos (2011) investigou o grau de aderência das empresas que compõem o Índice Bovespa em 2011 em relação ao CPC 04 - Ativo Intangível. Os principais resultados apontam que, de modo geral, as empresas não evidenciam suas informações de acordo com o sugerido no referido CPC.

Silva, Soeiro e Araújo (2013) analisaram a aderência das empresas do segmento Nível 1 da Governança Corporativa da BM\&FBOVESPA com relação a evidenciação do CPC 12 - Ajuste a Valor Presente. A amostra compreendeu 32 empresas e os resultados apontam um baixo grau de aderência das empresas estudadas ao CPC 12 - Ajuste a Valor Presente, comprometendo a qualidade da informação contábil-financeira, bem como a transparência de suas práticas contábeis.

Para as empresas do mercado de ações brasileiro, a Deliberação CVM no 691 de 8 de outubro de 2012 é o mecanismo que norteia a evidenciação das informações sobre os contratos de construção, equivalente ao pronunciamento contábil CPC 17. Essa deliberação descreve quais são as informações exigidas às empresas de capital aberto participantes da BM\&FBOVESPA em notas explicativas no que se refere às receitas aferidas com contratos de construção aos seus investidores. Assim, atendendo ao regime de competência, receitas esperadas de investimentos presentes não serão evidenciadas na demonstração do Balanço Patrimonial (BP) nem na Demonstração do Resultado do Exercício 
(DRE). Mas, com a descrição em notas explicativas da dinâmica dos contratos de construção e explicações sobre distorções de resultados presentes.

Como esse processo de evidenciação das informações sobre contratos de construção contempla um alto grau de complexidade por reformular significativamente as práticas contábeis no Brasil, a adoção inicial da Deliberação CVM n‥ 691/12 talvez não seja atendida por algumas empresas em decorrência do pouco tempo para a adaptação a essa reformulação. Assim, o objetivo da presente pesquisa é identificar o grau de aderência na evidenciação, em notas explicativas, dos contratos de construção segundo a Deliberação CVM no. 691/12 em empresas brasileiras de capital aberto do segmento de Construção Civil.

O estudo ajuda a preencher lacunas relacionadas ao entendimento do processo de evidenciação dos contratos de construção. Especificamente, quando se consideram as empresas de capital aberto do segmento de Construção Civil, não foram encontrados estudos que tratassem, especificamente, sobre o tema, o que apresenta uma possibilidade profícua de inserir esta temática na discussão teórica e, consequentemente, na verificação empírica no campo da contabilidade para usuários externos.

\section{PLATAFORMA TEÓRICO-EMPÍRICA}

\section{EVIDENCIAÇÃO DA INFORMAÇÃO CONTABILIDADE}

O objetivo da informação contábil tem sido amplamente discutido na área da contabilidade. Paton (1922) afirmava que a função da contabilidade e dos princípios e procedimentos contábeis devem ser expostos em termos da necessidade dos proprietários. American Accounting Association, AAA, (1966) descreve que o processo de identificação, mensuração e divulgação da informação contábil permite a realização de julgamento e decisões pelos usuários da informação. O Accounting Principles Board no 4, APB, (1970) destaca que a função dos serviços contábeis é fornecer informações quantitativas sobre a entidade cuja finalidade é permitir a tomada de decisão (HENDRIKSEN; VAN BREDA, 2009). Por fim, o CPC 01 R1 (2011) relata que o objetivo do relatório contábil é fornecer informações a cerca da entidade que sejam uteis para que os usuários externos possam tomar suas decisões.

Portanto, verifica-se que a premissa que permeia o objetivo da informação contábil evoluiu com o passar dos anos. Inicialmente a informação se restringia a necessidade dos proprietários da entidade (PATON, 1922). Com o decorrer dos anos, a informação passou a atendem os outros usuários externos da contabilidade (AAA, 1966). Outra evolução observada, refere-se a característica da informação, primeiramente, ela se restringia em fornecer informações quantitativas (APB, 1970), porém atualmente, o grande enfoque da informações passou a ser a característica qualitativa (CPC 00 R1, 2011).

A informação contábil deve evidenciar fatos relevantes e essenciais que não ofusquem nem confundam seus usuários no processo de decisão (IUDíCIBUS, 2000). Para que as informações contabeis sejam evidenciadas de forma correta é necessário que os eventos, primeiramente, sejam reconhecidos de acordo com o regime de competência, ou seja, as receitas, os custos e as despesas devem ser 
evidenciados no período auferido ou incorrido e não no momento em que são pagos.

Além disso, as informações contábeis deverão ser disponibilizadas em tempo hábil, possibilitando a tomada de decisão no momento do ocorrido atendendo suas características qualitativas. O CPC 00 R1 (2011) classifica as características qualitativas em: fundamentais e de melhoria. As características fundamentais referem-se a relevância e a representação fidedigna. Por relevância, entende-se a informação que é capaz de fazer a diferença nas decisões tomadas pelos usuários. Essa diferença é conquistada, somente, quando a informação possui valor preditivo e valor como feedback.

Para que o usuário possa confiar plenamente nas demonstrações contábeis é essencial que as mesmas evidenciem fielmente o que pretendem representar. Para ser fidedigna, a informação deve possuir três critérios: ser completa, neutra e livre de erros. Uma informação completa deve apreciar todos os dados necessários para que o usuário compreenda o fenômeno a ser retratado. A informação é neutra quando não carrega consigo nenhum viés que possa influenciar a decisão do usuário. E livre de erro quando é obtida por meio de métodos confiáveis (HENDRIKSEN; VAN BREDA, 2009).

As características de melhoria tem a finalidade de auxiliar na determinação do melhor método a ser utilizado quando a informação contábil apresenta-se no mesmo patamar de relevância e representação fidedigna. São subdivididas em quatro: comparabilidade, verificabilidade, tempestividade e compreensibilidade. A comparabilidade é uma característica que permite que os usuários identifiquem e compreendam similaridade nos itens e diferença entre eles. Todavia, é preciso tomar certos cuidados quando se pretende realizar comparações. Por exemplo, na análise de demonstrações contábeis é importante que os dados analisados estejam comparados com o mesmo trimestre do ano anterior, em virtude da sazonalidade das empresas (CPC 00 R1, 2011).

A verificabilidade ajuda a assegurar ao usuário que a informação representa o fenômeno econômico que se propõe a representar, em outras palavras, significa que diferentes observadores podem chegar a um consenso sobre determinada informação. A tempestividade significa que as informações disponíveis para tomar decisões devem vir a tempo de influenciar as decisões. Em geral a informação mais antiga é a que possui menos utilidade. No entanto, a pressa na disponibilização da informação pode fornecer dados precários e duvidosos, perdendo assim, a confiabilidade. A última característica de melhoria refere-se à compreensibilidade, significa que nas demonstrações contábeis devem apresentar as informações com clareza e concisas. A premissa básica da compreensibilidade pressupõe que os usuários possuem um mínimo de conhecimento de negócio para interpretar as informações disponibilizadas (CPC 00 R1, 2011).

Em síntese, a evidenciação das informações contábeis reduz a assimetria de informações no mercado e, consequentemente, os riscos dos investidores em cometerem erros em suas decisões (QUINTEIRO, 2004). Entre as forma de evidenciação das informações contábeis, estão às notas explicativas. Para ludícibus (2009) as notas explicativas tem a função de completar as informações que não podem ser evidenciadas nos demonstrativos contábeis. Em 
conformidade com o Pronunciamento Técnico CPC 26 (2011) a estrutura das notas explicativas devem:

a) Apresentar informação acerca da base para a elaboração das demonstrações contábeis e das políticas contábeis específicas utilizadas;

b) Divulgar a informação requerida pelos Pronunciamentos, Orientações e Interpretações que não tenha sido apresentada nas demonstrações contábeis; e

c) Prover informação adicional que não tenha sido apresentada nas demonstrações contábeis, mas que seja relevante para sua compreensão.

Portanto, as notas explicativas devem conter informações, relevantes, complementares e/ou suplementares às não suficientemente evidenciadas ou não constantes nas demonstrações contábeis propriamente ditas (OLIVEIRA, 2012).

\section{O SETOR E CONTRATOS DE CONSTRUÇÃO CÍVIL}

O conceito de eficiência, fundamental para o entendimento da AED, é um conceito relativo, pois compara o que foi produzido, dado os recursos disponíveis, com o que poderia ter sido produzido com os mesmos recursos (MELLO et al., 2005). Na Análise Envoltória de Dados, considera-se que uma DMU é $100 \%$ eficiente quando apresentar uma relação ótima de transformação de inputs em outputs, ou seja, quando não for possível melhorar o desempenho da DMU sem que seja piorado o desempenho de outra DMU. Por essa definição, não é necessária a determinação de preços ou pesos para refletir a importância dessas variáveis, assim como se evita também a necessidade de especificar explicitamente as relações formais que supostamente existem entre elas (COOPER et al., 2011).

A indústria da construção civil se difere dos outros ramos industriais por particularidades relativas a forma de produção e pelo produto. O setor tem relevância no setor econômico e social do país, fato este concluído pela extencia de sindicatos e associações próprias no pais. O produto da construção tem características singulares, pois cada obra é única com características próprias; tem características de imobilidade resultando em um bem imóvel que não pode ser transportado então localizado em espaço específico; e tem características de heterogeneidade, pois a indústria pode produzir diversos produtos com características diferentes para atender à necessidade que justifica sua produção (KNACKFUSS, 2010).

Segundo dados da Câmara Brasileira da Indústria da Construção, a construção civil empregou 3.015.373 trabalhadores na construção civil em 2012, sendo que a Região Sudeste, com 1.452.688 trabalhadores no setor, a mais representativa. Em 2013, a indústria teve $25 \%$ de participação no valor adicional bruto, sendo que a construção civil representa 5,4\% deste índice.

A construção civil é uma atividade com particularidades próprias que vem crescendo amplamente nos últimos anos. A Construção civil é a atividade de inclusão social de trabalhadores, pois não exige grande qualificação da mão-deobra nem certificações complexas para a contratação. Com o advento das iniciativas governamentais para aceleração do crescimento do pais, a atividade ganhou destaque no mercado (SPECK, 2011). 
A obra é o objeto dos contratos de construção civil. O contrato de Obra de Construção Civil segue o Pronunciamento Técnico CPC - 17 - Contratos de construção aprovada pela deliberação CVM no 691, de 8 de novembro de 2012 e pela Resolução CFC no 1.411/12 a qual deu nova redação a NBC TG 17 e revogou a Resolução CFC no 1171/09.

A Deliberação CVM no 691/2012 destaca que nas demonstrações contábeis o montante da receita, os métodos usados para sua determinação do contrato reconhecida no período e os métodos utilizados para determinar o estágio de execução dos contratos em curso devem ser divulgados.

Para os contratos em andamento, a Deliberação CVM no 691 orienta a divulgação dos custos incorridos e os lucros reconhecidos até a data, os adiantamentos recebidos e o montante de retenção. A apresentação das demonstrações contábeis deve considerar como ativo, o valor bruto devido pelo contratante da obra, ou seja, trabalhos executados descritos no contrato e não recebidos ou cobrados e; como passivo, o valor bruto devido pela contratada, ou seja, pela entidade, sobre serviços contratados e recebidos e não executados.

Considera-se, segundo o Pronunciamento Técnico CPC-17, que valor bruto referente aos serviços ainda não executado devido ao contratante é o montante líquido dos custos incorridos mais lucros reconhecidos; menos a soma das perdas reconhecidas e dos faturamentos em andamento. Já o valor bruto referente aos serviços executado devido pelo contratante é o montante líquido dos custos incorridos mais lucros reconhecidos; menos a soma das perdas reconhecidas e dos faturamentos em andamento.

\section{EXIGÊNCIAS DA DELIBERAÇÃO CVM 691/2012 E ANÁLISE DAS NORMAS CONTÁBEIS DE INTERPRETAÇÃO E ORIENTAÇÃO TÉCNICA}

Um dos modelos clássicos para aplicação da Análise Envoltória de Dados foi apresentado por Charnes et al. (1978), que sugeriram o Modelo CCR (Modelo de Charnes, Cooper e Rhodes) para avaliação das atividades de entidades sem fins lucrativos (DMUs) participantes de programas públicos. Esse modelo foi concebido inicialmente com orientação a entradas (inputs), e trabalha com retorno constante de escala, ou seja, variações nos inputs provocam variações proporcionais nos outputs (Charnes et al., 1978).

A Deliberação CVM 691/2012 está associada às Normas Internacionais da Contabilidade (IAS 11). A preocupação da Deliberação é especificar a divulgação de receitas e despesas no período de execução da obra. No próprio texto referente aos objetivos da Deliberação CVM 691/2012 há a referência do assunto primordial da norma que é a alocação de receitas e despesas correspondentes ao longo dos períodos de execução da obra nos quais o trabalho de construção é levado a efeito. A Interpretação Técnica ICPC 02 - Contratos de Construção do Setor Imobiliário e a Orientação OCPC 04 - Aplicação da Interpretação Técnica ICPC 02 às Entidades de Incorporação Imobiliária Brasileira direcionam as receitas e despesas e o tratamento contábil segundo o serviço negociado indicando os casos em que as receitas e despesas são contabilizadas segundo o Pronunciamento CPC 17- Contratos de Construção, ou quando o tratamento é segundo o Pronunciamento CPC 30- Receitas. 
A ideia passada pela Interpretação Técnica ICPC 02 e Orientação OCPC 04 é a referência e delimitação do alcance do Pronunciamento CPC 17, e consequentemente da Deliberação CVM 691/2012. Claramente a deliberação limita seu alcance para as entidades contratadas, ou seja, para os fornecedores dos serviços. Ao definir contratos de construção, a deliberação divide em dois os tipos de contratos de construção: os de preço fixo e os de custo mais margem. Por exemplo, ao visualizar a minuta do contrato do Programa Minha Casa, Minha Vida, pode ser verificado que o tratamento contábil para obra pronta é segundo o Pronunciamento CPC 30; mas, se a obra será construída, o contrato tem tratamento segundo o Pronunciamento CPC 17, seguindo o que estabelece a Deliberação CVM 691/2012.

A Deliberação CVM 691/2012, é clara em disser que a contabilização deve ser feita pelo estágio concluído da obra respeitando a contabilização por competência. Logo, verifica-se a importância das notas explicativas para correção de valores presente corrigidos a ser contabilizados, pois a Deliberação dita que a mensuração receitas e despesas são corrigidas pelo método do valor justo.

A Deliberação estabelece quais informações são de suma importância para a divulgação pela entidade. Eles podem ser resumidos nos itens da Figura 1, a qual apresenta os detalhes das informações que serão verificadas nas demonstrações contábeis.

Figura 2 - Diagrama representativo dos itens exigidos na Deliberação CVM 691/12 


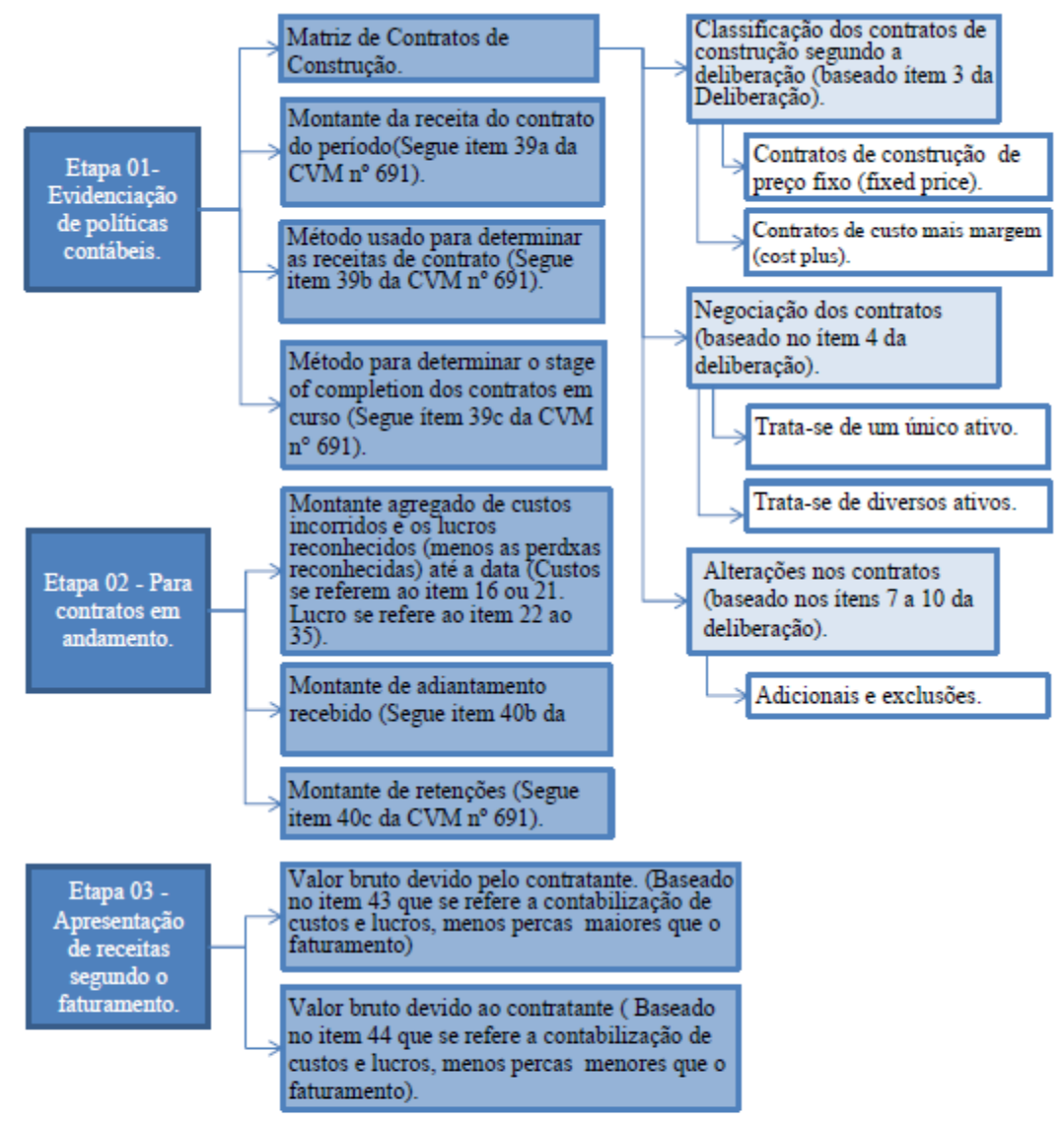

Etapa 04-Divulgação de passivos

contingentes e ativos contingentes.

Etapa 05 - Variações de receitas e despesas no periodo

Fonte: Adaptado da Deliberação CVM 691/12.

A Figura 1 representa o resumo das informações exigidas na deliberação. A norma divide os itens que devem ser divulgados em 4 (quatro) grupos, todas elas fundamentadas em itens da publicação.

\section{PERCURSO METODOLÓGICO}

O objetivo da pesquisa tem propriedade descritiva. Beuren (2008) trata que pesquisa descritiva é aquela que descreve aspectos ou comportamentos de uma amostra analisada sendo assim classificada. Portanto, a pesquisa busca descrever o grau de aderência na evidenciação, em notas explicativas, dos contratos de construção segundo a Deliberação CVM no. 691/12.

Os procedimentos são documentais e bibliográficos. Os dados foram coletados e tratados por meio do método quantitativo e qualitativo. Creswell (2010) denomina a pesquisa qualitativa e quantitativa como pesquisa de método misto. Muito comum nas ciências sociais, a natureza interdisciplinar dos pesquisadores contribui para a formação de pesquisas que englobam característica de coleta, análise, interpretação e redação dos resultados de um 
tema utilizando procedimentos quantitativos como, por exemplo, atribuição de índices para ilustrar as conclusões da pesquisa.

A população da pesquisa pode ser definida, segundo Beuren (2006, p. 118), como a coleção de "elementos distintos que contêm certo número de características comuns". Amostra é definida por Lakatos (2007, p. 41) como a "porção ou parcela, convenientemente selecionada do universo (população) ". A população do estudo é definida pelas empresas de capital aberto participantes da BM\&FBOVESPA classificadas no segmento da Construção Civil, sendo o campo amostral baseado na participação dessas empresas na composição da carteira do Índice BM\&FBOVESPA Imobiliário (IMOB). A amostra da pesquisa se restringe as empresas do segmento de Construção Civil mais representativas do índice IMOB, totalizando 5 empresas. A amostra deu-se de forma não probabilista, por conveniência. Para Gil (2003) nesse tipo de amostragem o pesquisador obtém, a partir de um número de elementos, a representação adequada da população. $\mathrm{A}$ Tabela 1 apresenta as empresas que compõem a amostra da pesquisa.

Tabela 1: Empresas que representam a amostra da pesquisa

\begin{tabular}{cccc}
\hline Ação & $\begin{array}{c}\text { Quantidade } \\
\text { Teórica }\end{array}$ & $\begin{array}{c}\text { Participação (\%) no } \\
\text { IMOB }\end{array}$ & $\begin{array}{c}\text { Participação (\%) } \\
\text { Acumulada }\end{array}$ \\
\hline CYRELA & 181.248 .160 & 6,438 & \\
REALT & & & \\
MRV & 303.481 .955 & 5,869 & $25,32 \%$ \\
PDG REALT & 1.300 .363 .699 & 4,756 & \\
EVEN & 213.960 .535 & 4,177 & \\
GAFISA & 416.977 .076 & 4,082 & \\
\hline
\end{tabular}

Fonte: Dados da pesquisa (2017). 
A Tabela 1 apresenta que a abrangência da amostra é no total de $25,32 \%$ do índice IMOB, sendo cada empresa com sua participação percentual representada na coluna cujo nome é Part (\%) no IMOB, ou seja, a participação percentual no Índice BM\&FBOVESPA Imobiliário. $O$ instrumento de pesquisa é formatado com base nas exigências no que diz respeito a divulgação das receitas e despesas referentes aos contratos de construção identificadas na análise minuciosa da Deliberação CVM 691/2012 resultante em uma tabela que resume as informações relevantes que deve ser apresentada nas notas explicativas das Demonstrações Contábeis.

O resumo das informações relevantes determina índices para a avalição quantitativa do nível de evidenciação obtido nas notas explicativas. Sendo assim, determinou que a mensuração do nível da evidenciação das notas explicativas se dá por meio da avaliação positiva ou negativa dos dados da coluna "Itens da Deliberação CVM 691/2012" da Tabela 2 para cada amostra. Assim sendo, a Tabela 2 é o instrumento de pesquisa resultante do resumo das informações exigidas na Deliberação CVM 691/2012 e da definição da variação dos índices de avaliação da evidenciação das notas explicativas. A determinação positiva é numerada pelo número 1 (um), e a determinação negativa é atribuído o valor 0 (zero).

A técnica de coleta de dados se baseia, inicialmente, pelo estudo dos critérios de reconhecimento das receitas descritos na Deliberação CVM 691/2012 para, resumidamente, formatar as formas de reconhecimento dos dados e a descrição do método quantitativo de aferição do nível de evidenciação das notas explicativas das empresas estudadas no que se refere aos contratos de construção.

A coleta de dados foi realizada a partir da divulgação das Demonstrações Financeiras Anuais de 2013 pelas empresas no site da BM\&FBOVESPA. As notas explicativas fazem parte das demonstrações contábeis e podem ser analisadas separadamente das outras demonstrações. Mesmo assim, a leitura de todas as demonstrações contábeis é realizada para avaliação apuradas da evidenciação dos contratos estão seguidos às recomendações da Deliberação CVM 691/2012.

\section{DESCRIÇÃO E ANÁLISE DE DADOS}

Após a seleção das variáveis, aplica-se a AED também com auxílio do software Microsoft Excel 2010. Nessa etapa, o Modelo CCR foi utilizado para a geração de índices que quantificam a eficiência de cada prato na transformação das variáveis de entrada em variáveis de saída. Essa relação pode ser vista também como o quanto cada prato onera a cozinha e estruturas de apoio ao ser preparado, uma vez que um prato mais eficiente utiliza menos recursos para ser produzido.

A avalição da pesquisa começou a com a busca das cinco empresas do campo amostral. Cada empresa na bolsa de valores recebe classificações, e dentro destas classificações, há o segmento das empresas da Construção Civil. Em abril, estão registradas na Bolsa de Valores, Mercadorias e Futuros de São Paulo vinte empresas nesta classificação.

Confrontaram-se as empresas listadas no seguimento da construção civil com as empresas apresentadas na composição do índice IMOB da 
BM\&FBOVESPA e verificou-se que a as cinco maiores empresas desta composição são: CYRELA, MRV, PDG Realt, EVEN e GAFISA.

Pesquisou nas notas explicativas das referidas empresas e analisaram-se os parâmetros qualitativos descritos nos cinco quadros para cada empresa separadamente. Com base nesta análise pontuou as empresas conforme descrito o método de análise dos dados sendo que, os resultados da análise qualitativa resultaram nos dados apresentados na forma quantitativa no Quadro 01.

Tabela 2: Medição do Nível de Evidenciação das Notas Explicativas

\begin{tabular}{|c|c|c|c|c|c|}
\hline Dados de avaliação & Cyrela S.A. & MRV & PDG Realt & Even & Gafisa \\
\hline \multicolumn{6}{|c|}{ Etapa 01 - Evidenciação de políticas contábeis } \\
\hline \multicolumn{6}{|c|}{ Matriz de Contratos de Construção. } \\
\hline $\begin{array}{l}\text { Classificação dos contratos } \\
\text { construção segundo a deliberação. }\end{array}$ & 0 & 1 & 0 & 0 & 0 \\
\hline Negociação dos contratos & 1 & 1 & 1 & 1 & 1 \\
\hline Alterações nos contratos & 1 & 1 & 1 & 1 & 1 \\
\hline Montante da receita do contrato do período. & 1 & 1 & 0 & 1 & 0 \\
\hline $\begin{array}{l}\text { Método usado para determinar as receitas de } \\
\text { contrato. }\end{array}$ & 1 & 1 & 1 & 1 & 1 \\
\hline $\begin{array}{l}\text { Método para determinar o stage of completion } \\
\text { dos contratos em curso. }\end{array}$ & 1 & 1 & 1 & 1 & 1 \\
\hline \multicolumn{6}{|c|}{ Etapa 02 - Para contratos em andamento. } \\
\hline $\begin{array}{l}\text { Montante agregado de custos e os lucros } \\
\text { reconhecidos. }\end{array}$ & 1 & 1 & 1 & 1 & 1 \\
\hline Montante de adiantamento recebidos. & 1 & 1 & 1 & 1 & 1 \\
\hline Montante de retenção & 1 & 1 & 1 & 1 & 1 \\
\hline \multicolumn{6}{|c|}{ Etapa 03 - Apresentação de receitas segundo o faturamento } \\
\hline Valor bruto devido pelo contratante. & 0 & 1 & 0 & 0 & 1 \\
\hline Valor bruto devido ao contratante. & 0 & 1 & 0 & 0 & 1 \\
\hline $\begin{array}{l}\text { ETAPA } 04-\text { Divulgação de passivos } \\
\text { contingentes e ativos contingentes. }\end{array}$ & 1 & 1 & 1 & 1 & 1 \\
\hline $\begin{array}{l}\text { ETAPA } 05 \text { - Variações de receitas e despesas no } \\
\text { período. }\end{array}$ & 1 & 1 & 1 & 1 & 1 \\
\hline Nível de evidenciação das Notas Explicativas & $76,92 \%$ & $100,00 \%$ & $69,23 \%$ & $76,92 \%$ & $84,62 \%$ \\
\hline
\end{tabular}

Fonte: Dados da pesquisa (2017).

A análise de dados demostram que as emprestas de capital aberto no seguimento da construção civil evidenciam no mínimo em $69,23 \%$ dos itens exigidos na Deliberação CVM no691/12 e no máximo 100\% dos itens. A evidenciação média entre as empresas do seguimento resulta no nível de evidenciação de $81,54 \%$.

$\mathrm{Na}$ análise do contesto histórico das empresas no ano da análise de dados, a empresa GAFISA vendem parte da empresa que controlava para fazer caixa frete aos resultados negativos dos anos passados publicados justificado o segundo mais alto nível de evidenciação entre as amostras. A empresa PGD entrou no 
mercado de ações e seu primeiro demonstrativo anual foi o analisado, justificando o mais baixo nível de evidenciação.

Com relação a Etapa 01 - Evidenciação de politicas contábeis, constatou-se que apenas a empresa MRV apresentou todas as informações exigidas pela deliberação. Notou-se a ausência de evidenciação da classificação dos contratos de construção por quatro empresas e a divulgação do montante da receita do contrato do período pela PDG Real e Gafisa.

De forma integral, todas as empresas analisadas evidenciaram os contratos em andamento (Etapa 02). Na Etapa 03 - Apresentação das receitas segundo o faturamento, apenas as empresas MRV e Gafisa evidenciaram as informações sobre o valor bruto devido pelo contratante e ao contratante. Ressalta-se que a Etapa 04 - Divulgação de passivos contingentes e ativos contingentes e a Etapa 05 - Variações de receitas e despesas no período, os requisitos foram atendidos totalmente pelas empresas da amostra.

Portanto, verificou-se que embora a Deliberação CVM 691/12, sugerir a evidenciação das informações sobre contrato de construção, os resultados fornecem indícios que a adoção ainda não é completa no que refere-se as empresas do segmento de construção civil. Estando apenas uma empresa (MRV) com as informações evidenciadas completamente. Assim, nota-se sintonia dos resultados encontrados com estudos de Barcelos (2011) e Silva, Soeiro e Araújo (2013) no que refere-se a aderência as normais internacionais. Percebe-se que as empresas levam algum tempo para se adequar a mudanças contábeis.

\section{CONSIDERAÇÕES FINAIS}

A pesquisa apresentou como objetivo, identificar o grau de aderência na evidenciação, em notas explicativas, dos contratos de construção segundo a Deliberação CVM n‥ 691/12 em empresas brasileiras de capital aberto do segmento de Construção Civil. Para isso foram analisadas as 5 empresas do segmento de construção civil com maior representatividade no Índice BM\&FBOVESPA Imobiliário.

A pesquisa caracterizou-se como descritiva quanto ao objetivo e bibliográfica e documental quanto aos procedimentos, além que tratar de um estudo qualitativo e quantitativo. $O$ instrumento de pesquisa foi construído com base nas informações extraídas da Deliberação CVM no 691/12 no que refere-se as exigências de divulgação em notas explicativas dos contratos de construção.

A priori, os resultados apontaram que apenas uma das empresas analisadas evidenciaram todas as informações sugeridas pela deliberação. Notou-se, também, que a principal ausência de informações refere-se a classificação dos contratos (Etapa 01), montante de receitas dos contratos (Etapa 02) e valor bruto devido pelo contratante e ao contratante (Etapa 3). As Etapas 04 e 05 foram atendidas integralmente pelas empresas analisadas.

Em síntese, nota-se que os resultados convergem com estudos na área (BARCELOS, 2011; SILVA; SOEIRO; ARAÚJO, 2013), uma vez que é notório que nos primeiros anos de adequação as normas internacionais as empresas não evidenciem todas as informações sugeridas pelas normas. 
Ressalta-se que os resultados encontrados são limitados pela amostra empregada, bem como, a metodologia utilizada. Sugere-se para futuras pesquisas, a ampliação da amostra, assim como a expansão dos períodos analisados, a fim de, identificar se os resultados evidenciados na pesquisa ainda convergem com a realidade atual das empresas. 


\title{
LEVEL OF ADHERENCE IN THE EVIDENTIATION OF THE EXPLANATORY NOTES OF CONSTRUCTION CONTRACTS ACCORDING TO THE CVM RESOLUTION №. $691 / 12$
}

\author{
ABSTRACT
}

The objective of the research is to identify the degree of adherence to the disclosure, in explanatory notes, of construction contracts according to CVM Resolution no. 691/12 in Brazilian publicly traded companies in the Civil Construction segment. In order to do so, we analyzed the companies in the construction segment with the highest representation in the BM \& FBOVESPA Real Estate Index. The research was characterized as descriptive regarding the objective and bibliographic and documentary regarding the procedures, besides that of a qualitative study. The research instrument was constructed based on the information extracted from CVM Deliberation 691/12. The results suggest that only one of the companies analyzed evidenced all the information suggested by the deliberation (MRV). It was also noted that the main lack of information refers to the classification of contracts (Step 01), amount of contract revenues (Step 02) and gross value payable by the contractor and the contractor (Step 3). Steps 04 and 05 were fully met by the companies analyzed.

KEYWORDS: Accounting evidence. Construction Segment. Explanatory Notes. 
AAA, AMERICAN ACCOUNTING ASSOCIATION. A statement of basic accounting theory. ASOBAT. Florida: American Accounting Association, 1966.

BARCELLOS, M. Aderência das empresas o índice Bovespa nos anos de 2009 a 2010, em termos dos itens de divulgação em notas explicativas estabelecidos no pronunciamento técnico CPC 04 (R1). 2011, 73 f. Trabalho de Conclusão de Curso (Universidade Federal de Santa Catarina) - Departamento de Ciências Contábeis, UFSC, 2011.

BEUREN, I. M., et al. Como Elaborar Trabalhos Monográficos em Contabilidade. 3. ed. São Paulo: Atlas, 2008.

BRAGA, H. R.; ALMEIDA, M. C. Mudanças contábeis na Lei Societária: Lei no 11638, de 28-12-2007. 1ạ ed. São Paulo: Atlas, 2009.

BRASIL. Comissão de Valores Mobiliários - Deliberação CVM 691 de 08 de novembro de 2012. Disponível em:

<http://www.cvm.gov.br/asp/cvmwww/atos/Atos_Redir.asp?Tipo=D\&File=\ deli\deli691.doc>. Acesso em: 30 maio. 2017.

CPC, Comitê de Pronunciamentos Contábeis. Estrutura conceitual para a elaboração e apresentação das demonstrações contábeis. 2011. Disponível em: www.cpc.org.br/pdf/CVM_CPC.pdf. Acesso em 08 jun. 2017.

CRESWELL, J. W. Projeto de Pesquisa: Métodos quantitativos, qualitativos e mistos. 3a ed. Porto Alegre: Artmed, 2010.

FASB, Financial Accounting Standards Board. Statement of financial accounting standards no 1. Objectives of Financial Reporting by Business Enterprises. Stamford, Connecticut, 1978.

GIL, A. C. Elaborar Projetos de Pesquisa. 3a ed. São Paulo: Atlas, 1996.

HENDRIKSEN, E. S.; VAN BREDA, M. F. Teoria da contabilidade. 5ạ. ed. São Paulo: Atlas, 2007.

IUDÍCIBUS, S. de . Teoria da Contabilidade. 9ạ ed. São Paulo: Atlas, 2009. 
KNACKFUSS, M. G. Construção na Economia Brasileira: Participação do setor no investimento nacional. 2010. Ed. UFRGS. Disponível em:

<http://www.lume.ufrgs.br/bitstream/handle/

10183/28588/000769201.pdf?sequence=1>. Acesso em 05 set. 2017.

LAKATOS, E. M.; MARCONI, M. de A.. Fundamentos de Metodologia Científica. 4ạ ed. São Paulo: Atlas, 2001.

NIYAMA, J. K.; SILVA, C. A. T. Teoria da Contabilidade. São Paulo: Atlas, 2011.

OLIVEIRA, L. M. de. et al. Manual de Contabilidade Tributário: textos e testes com as respostas. 11a ed. São Paulo: Atlas, 2012.

OLIVEIRA, V. A.; LEMES S. "Nível de convergência dos princípios contábeis brasileiros e norte-americanos às normas do IASB: uma contribuição para a adoção das IFRS por empresas brasileiras." Revista Contabilidade e Finanças v. 22.n. 56 (2011): 155-173. crossref

OLIVEIRA, V. F. ; OLIVEIRA, E. A. de A. D.. O Papel da Industria da Construção Civil na Organização do Espaço e do Desenvolvimento Regional. São Paulo: Unindu, 2012.

QUINTEIRO, L. G. L. A relação entre a evidenciação de informações contábeis e a volatilidade dos retornos das ações no Brasil. In: CLADEA, 39., 2004, República Dominicana. Anais... República Dominicana: CLADEA, 2004. CD-ROM.

SILVA, R. C.; SOEIRO, T. M.; ARAÚJO, J. G. N. Um estudo da adequação ao pronunciamento técnico CPC 12 - Ajuste ao valor presente em empresas brasileiras listadas no segmento Nível 1 (N1) de governança corporativa da BM\&FBOVESPA. CONGRESSO NACIONAL DE CIÊNCIAS CONTÁBEIS, 2013. Anais eletrônicos ... CONACIC, Maceió, 2013. Disponível em < www.euquerofits.com.br/conacic-2013/trabalhos/502.pdf >. Acesso em: 05 ago. 2017.

SPECK, R. M. Contabilidade da Construção Civil: Aspectos Contábeis e Fiscais conforme Legislação Tributária e sob o enfoque do CPC 17 - Contratos de Construção." Criciúma: Universidade do Extremo Sul Cararinense, julho de 2011. 
Recebido: 08 nov. 2016

Aprovado: 22 set. 2017

DOI: 10.3895/gi.v13n2.5006

Como citar:

PONTAROLO, D. M. A. et al. Nível de aderência na evidenciação das notas explicativas de contratos de construção segundo a deliberação cvm n 691/12. R. Gest. Industr., Ponta Grossa, v. 13, n. 2, p. 21-36, jun./ago. 2017. Disponível em: <https://periodicos.utfpr.edu.br/rgi>. Acesso em: XXX.

Correspondência:

Dylliane Maria Alessi Pontarolo

PR 153 Km 7 - Riozinho - CEP 84500-000, Irati, Paraná, Brasil

Direito autoral: Este artigo está licenciado sob os termos da Licença Creative Commons-Atribuição 4.0 Internacional.

(c) (1) 